\title{
AMNIOTIC BAND SYNDROME: A SILENT KNIFE IN-UTERO
}

\author{
Fatema $N^{1}$, Acharya $Y^{2}$, Yaqoubi HNA
}

${ }^{1}$ Department of Obstetrics and Gynaecology, Ibri Regional Hospital, Sultanate of Oman,

${ }^{2}$ Avalon University School of Medicine, Curacao, Netherlands Antilles

\begin{abstract}
Amniotic band syndrome (ABS) is a rare, but serious congenital syndrome complex. It is associated with a wide range of fetal structural anomalies, notably craniofacial and limb anomalies. Early prenatal diagnosis is important to provide accurate information to the parents, predict the prognosis and in some cases perform in-utero lysis of the bands to restore the blood flow to the affected limb. A postnatal multidisciplinary approach involving vascular decompression, reconstructive surgery, prosthesis, and physiotherapy are some of the therapeutic options. It is necessary to consider ABS in prenatal screening with a high index of suspicion as early screening can allow a timely therapeutic strategy and reduce the severity of the associated defects.
\end{abstract}

\section{KEYWORDS}

Amniotic band syndrome, ADAM complex, birth defects

\section{CORRESPONDING AUTHOR}

Dr. Yogesh Acharya

Assistant Professor,

Department of Epidemiology, Preventive and Evidence-

based Medicine

Research chair, Avalon University School of Medicine, Willemstad, Curacao, Netherlands Antilles,

Email: dryogeshach@gmail.com 


\section{INTRODUCTION}

Amniotic Band Syndrome (ABS), also known as amniotic band disruption complex or constriction band syndrome or amniotic deformity, adhesions, mutilations (ADAM) complex, amniotic band sequence, Streeter's dysplasia, congenital constriction bands or pseudoainhum, is a congenital malformation that includes the various degrees of limb defects with major craniofacial, thoracic, and abdominal involvement. ${ }^{1,2}$ Amniotic membranes are a protective structure for the fetus, but the presence of amniotic bands can cause varieties of fetal deformities, including fetal demise. ${ }^{3} \mathrm{ABS}$ is a usual consequence of an early amniotic sac rupture and carries significant structural morbidity. ${ }^{4}$

\section{MATERIALS AND METHODS}

The objective of this review is to provide a descriptive analysis of $\mathrm{ABS}$ and highlight the importance of early diagnosis owing to high associated morbidity and mortality. We methodically searched relevant articles from 'PubMed' and 'Google Scholar' databases. Nonspecific combination of keywords used to define and search these studies include: "amniotic band" OR "amniotic band syndrome" OR "epidemiology" OR "pathogenesis" OR "diagnosis" OR "management" OR "complications." One hundred and seventy peer reviewed studies were compiled and analyzed based on the search strategies. Fifty one amongst them that were in English language with free full text relevant to our study objectives were included for final draft.

\section{Epidemiology}

ABS is relatively common in the Afro-Caribbean population with the reported incidence of $1: 1,200$ to $1: 15,000$ live births and 1 in 70 stillbirths. $^{4}$ Approximately two-third has been reported in primiparous, with similar incidence in both male and female fetuses., ${ }^{5,6}$ There is no evidence of Mendelian inheritance and genetic linkage is yet to be explored.$^{7,8}$ Some of the identified risk factors include: high altitude (hypoxia), black race, primiparous, young maternal age, obesity, maternal drug abuse (cocaine, methadone, mifepristone, misoprostol), tobacco use, uterine malformation, acute febrile illness and hemorrhage during the first trimester, collagen vascular disease and previous history of uterine surgery. ${ }^{9-11}$ Diabetic vasculopathy may increase the risk of vascular disruption leading to amnion rupture. ${ }^{8}$

\section{Pathogenesis}

Pathogenesis is controversial and remains unclear. Majority of the cases are reported within the background of atypical gestational history. ${ }^{12}$ Two theories have been proposed: intrinsic and extrinsic hypothesis. The intrinsic or endogenous theory by Streeter (1930) explains the origin of the fibrous bands and anomalies as a consequence of a perturbation of developing the germinal disc of the early embryo. ${ }^{13}$ On the contrary, extrinsic or exogenous theory by Tropin (1966) suggested the development of defects by rupture of the amnion in early pregnancy through the formation of amniotic bands and loss of amniotic fluid, subsequently followed by an extrusion of all or parts of the fetus into the chorionic cavity. ${ }^{14}$ These bands entrap parts of the growing fetus, entangle, and subject to compression (Fig.1). Compression compromises fetal circulation, growth and development resulting in disturbances of structure and functions. Vascular disruptions are well supported by animal studies and give rise to many congenital malformations. ${ }^{15-17}$ A rare association between spontaneous septostomy in monochorionic diamniotic twin pregnancy is also reported..$^{18}$ Although both of these (intrinsic and extrinsic) mechanisms cannot explain many recognized defects, the extrinsic hypothesis is more widely accepted. ${ }^{6}$

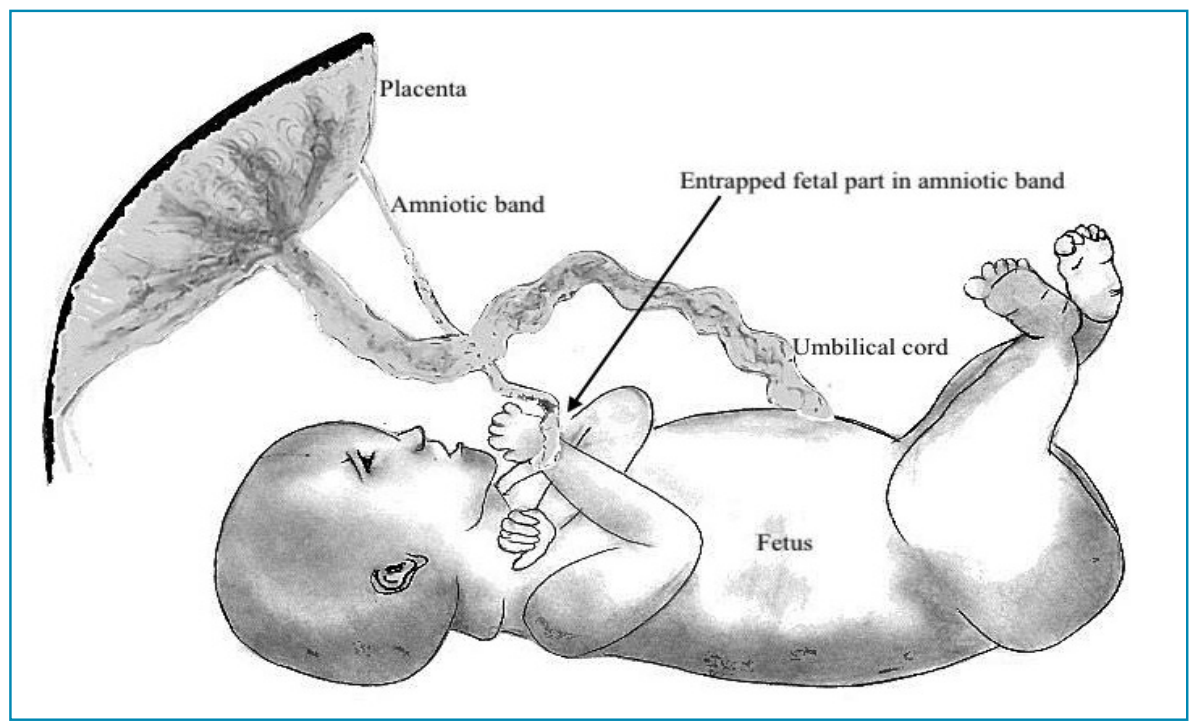

Fig.1: Pictorial representation of an entrapped fetal upper limb with amniotic band 
Diagnosis: Ultrasonography (USG) is the standard method of diagnosis in utero. ${ }^{19}$ Previous studies failed to demonstrate the gestational age at which it can be accurately predicted. ${ }^{5}$ A vigilant scan during the 1st trimester may visualize the presence of the amniotic band and its possible sequences (Fig. 2). Vestige sign ${ }^{9}$ at the amputated limb has a diagnostic utility, but visualization of the amniotic band is not always easy and requires meticulous follow up. Color doppler is indicated to rule out lymphatic and vascular complications. ${ }^{20}$

Traditionally, two-dimensional ultrasonography (2D USG) has been the choice but the three-dimensional ultrasonography (3D USG) rendering mode has been found to have an advantage in spatial analysis and visualization. ${ }^{21-26}$ 3D USG can also be employed for late diagnosis with added precision. Therefore, three or four dimensional ultrasound can be a better option to diagnose the amniotic band and associated fetal anomalies. Fetal magnetic resonance imaging (MRI) can be useful in the case of equivocal USG findings. ${ }^{6}$ band is not feasible owing to difficult membrane separation, use of gas $\left(\mathrm{CO}_{2}\right)$ can provide distension of the uterus to facilitate the more complex surgical procedures. ${ }^{31}$

Umbilical cord involvement places the fetus at a much higher risk for intrauterine fetal death (IUFD). Therefore, fetoscopic release for umbilical cord involvement should be considered in appropriate candidates without other contraindications to a fetal procedure. ${ }^{29}$ Fetoscopic band release is not preferred in patients with abdominal, limb-body wall complex (LBWC), thoracic, or cranial involvement as these are often diagnosed after significant irreversible deformity. ${ }^{32}$ It is best to consider fetoscopic laser treatment when blood flow is impaired but not completely absent. ${ }^{33}$ Successful blunt dissection is reported in only one case of non-adhesive amniotic bands. ${ }^{28}$

Careful planning of the trocar insertion site, avoidance of unnecessary movements, and minimal forces are advised during fetoscopic interventions.
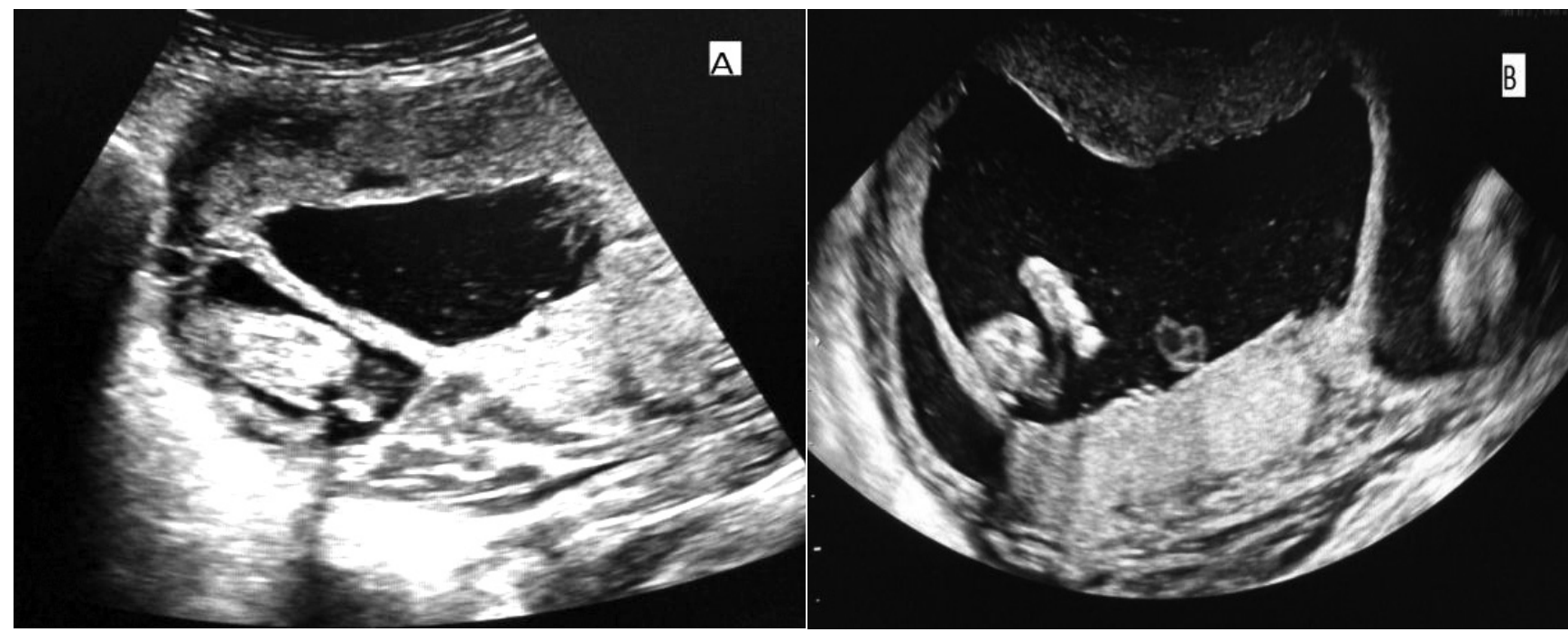

Fig. 2: Ultrasonography (USG) image showing the amniotic band in the fetus

(A: amniotic band floating in the amniotic fluid arising from the one end of the placenta extending to the other part of amnion, B: clearly visible double amniotic bands)

Management: Termination of the fetus is not advocated but a selective termination of the affected fetus in case of a dichorionic diamniotic twin pregnancy has been reported with favorable outcome of the healthy fetus. ${ }^{27}$ Fetoscopic intervention and release of the band is the most accepted approach in well-defined cases. ${ }^{28}$ But it is usually reserved for a single limb involvement, and previous experiences are limited to case reports and series. ${ }^{29}$ Fetoscopic approach with minimally invasive surgery or laser to release the amniotic band remains an alternative and may salvage the fetal life or limb with the desired functional outcome. ${ }^{6}$ There is a potential for bone growth and functional limb preservation was reported in $50 \%$ of cases with fetoscopic amniotic band release, $71 \%$ with most of the interventions performed with laser dissection and 14\% with endoscopic scissors. ${ }^{28,30}$ If the release of the amniotic
Patients should be fully informed about the risks and benefits. Potential complications, like postoperative subchorionic bleeding and membrane separation with amniotic fluid loss can result within the first 24 hours after surgery. This can lead to preterm premature rupture of membrane (PPROM) leading to preterm delivery. However, the risk depends on the number and diameter of the ports used and duration of the procedure $(6-30 \%$ in the single access to nearly $50 \%$ in $>1$ ports). ${ }^{34}$

Reconstructive surgeries, like microvascular hand to toe transfer, are viable options for the baby born with the structural deformity. ${ }^{35}$ But the consensus regarding the ideal time for the plastic and reconstructive surgical procedures after birth in the background of ABS is lacking. Although emergency surgery is recommended within $48 \mathrm{hrs}$, 
delay in surgery till six months is justified based on the favorable aesthetic outcome and technical limitations. ${ }^{36,37}$

Complications: ABS usually affects the extremities, fingers and toes are commonly involved..$^{32,38}$ The severity of the defects depends on the anatomical location of the amniotic band. ${ }^{1}$ A wide range of fetal structural anomalies arises as potential complications, ranging from simple cosmetic abnormalities with superficial skin involvement to major craniofacial and limb anomalies with associations are still not completely deciphered. Guzmann $^{5}$ have proposed grouping system that classifies the ABS into four groups to aid in diagnosis (Table 2).

\section{DISCUSSION}

It is necessary to consider ABS in first-trimester scanning. ${ }^{20}$ Development in radiological imaging modalities and prenatal screening tests have made the prenatal diagnosis possible. During the

Table 1: List of different complications/anatomical defects as a consequence of ABS in fetus..$^{20,39}$

\begin{tabular}{|c|c|}
\hline \multicolumn{2}{|c|}{ Anatomical/structural defects of ABS $\dagger$} \\
\hline $\begin{array}{l}\text { Limb defects } \\
\text { - } \text { shortening of the extremities } \\
\text { - } \text { constrictions } \\
\text { - } \text { syndactyly } \\
\text { - } \text { pseudosyndactyly -hypoplasia } \\
\text { - distal lymphedema } \\
\text { - } \text { foot deformities } \\
\text { - } \\
\text { amputations }\end{array}$ & $\begin{array}{l}\text { Craniofacial defects } \\
\text { - } \text { facial distortion } \\
\text { - } \text { cleft lip and palate } \\
\text { - } \text { eye, ear, and/or nose } \\
\text { defects } \\
\text { - } \text { encephalocele } \\
\text { - } \text { facial cleft } \\
\text { - choanal atresia } \\
\text { - craniosynostosis } \\
\text { - } \text { ventriculomegaly and/or } \\
\text { - hydrocephalus } \\
\text { - } \text { holoprosencephaly } \\
\text { - decrania }\end{array}$ \\
\hline
\end{tabular}

\section{Other defects}

- adhesion of fetal parts to amniotic bands or to the placenta

- abdominal or thoracic wall defects

- ectopia cordis

- evisceration

- gastroschisis

- omphalocele

- short umbilical cord

- spinal column alterations

†Source: https://www.ncbi.nlm.nih.gov/pubmed/26810022,

https://www.ncbi.nlm.nih.gov/pubmed/27262732

Table 2: Table showing the classification of amniotic band sequence into four different groups (Group I-IV) based on associated structural defects ${ }^{5}$

\begin{tabular}{|c|c|c|c|}
\hline \multicolumn{4}{|c|}{ Amniotic band syndrome (ABS) $\dagger$} \\
\hline Group I & Group II & Group III & Group IV \\
\hline $\begin{array}{l}\text { Craniofacial + limb } \\
\text { defects }\end{array}$ & $\begin{array}{l}\text { Craniofacial + limb } \\
+ \text { abdominal wall, } \\
\text { spinal column, and/or } \\
\text { thoracic defects }\end{array}$ & $\begin{array}{l}\text { Limb + abdominal wall, } \\
\text { spinal column, and/or } \\
\text { thoracic defects }\end{array}$ & $\begin{array}{l}\text { Isolated defects } \\
\text { (craniofacial, limb, or } \\
\text { thoraco-abdominal wall) }\end{array}$ \\
\hline
\end{tabular}

$\dagger$ Source: https://www.ncbi.nlm.nih.gov/pubmed/24304730

constrictive bands, amputation and even decapitation (Table 1). ${ }^{20,39}$ Constrictive bands around the chest or abdomen result in wall defects and the most common cause of fetal demise is constriction of the umbilical cord. $^{40,41}$ Proximal bands are commonly associated with the compression of the nerves. ${ }^{42}$

ABS is also found to occur concomitantly with many other uncommon disorders, like aplasia cutis congenital, osteogenesis imperfecta, EhlersDanlos syndrome type IV, ethmocephaly, acalvaria, bilateral epibulbar choristoma. ${ }^{43-48}$ But many of these antenatal scan, detection of the amniotic band with associated fetal defects and restricted fetal limb movements are diagnostic. It is crucial for the management of current pregnancy and to reassure the patient regarding subsequent pregnancies about the sporadic nature of the condition with low recurrence. . $^{3,920,49}$ Undoubtedly, the prenatal diagnosis can reduce the severity of many associated anomalies, allowing a timely therapeutic strategy during pregnancy with fetoscopic band release or intervention immediately after birth. ${ }^{6}$ 
A fetus with amniotic band syndrome should be delivered in a tertiary care center where neonatologists, pediatric surgeons, and orthopedicians are available. ${ }^{20}$ Postnatal treatment options include surgical intervention to enhance function or for cosmetic purposes, and prosthesis and physiotherapy in individuals with limb defects. ${ }^{6}$ Treatment depends on the nature of amniotic band syndrome and the severity of deformation. Constriction band is released in mild limb constriction, while realignment surgeries are recommended in severe bony abnormalities. ${ }^{20}$

Structural abnormalities in ABS resemble genetic syndrome. ${ }^{49}$ Early prenatal diagnosis of ABS is important to provide accurate information to the parents, predict the prognosis and in some cases perform in-utero lysis of the bands to restore blood flow to the affected limb. ${ }^{33} \mathrm{~A}$ thorough evaluation of the umbilical cord and/or amniotic bands along with the fetal parts during early pregnancy is advocated..$^{50}$ Similarly, multidisciplinary approach involving early vascular decompression, reconstructive surgery, prosthesis, and physiotherapy is the best treatment modalities. ${ }^{51}$ Patients should be informed that ABS is a non-lethal condition in most cases and prenatal intervention carries significant fetal morbidity mainly linked to the consequences of
PPROM and preterm birth. The risk/benefit balance between in-utero and postnatal treatment needs to be discussed together with plastic and orthopedic surgeons and decision for intervention depends on clinical equipoise. ${ }^{9}$

In conclusion, $\mathrm{ABS}$ is a rare but serious congenital sequence complex that can result in various degrees of limb defects and major organ malformations. Prenatal diagnosis is possible with a high degree of suspicion in pregnant females with risk factors. Early diagnosis can reduce the severity of anomalies, allowing a timely therapeutic strategy during pregnancy and fetoscopic band release or other possible interventions immediately after birth.

\section{Learning points:}

1. ABS is a rare but serious congenital sequence complex.

2. A high degree of vigilance is required during prenatal screening.

3. Ultrasound is the most accepted method for inutero diagnosis.

4. Early diagnosis can reduce the complications by allowing flexible therapeutic options.

5. Postnatal multidisciplinary approach is necessary for the effective management.

\section{REFERENCES}

1. Graves CE, Harrison MR, Padilla BE. Minimally Invasive Fetal Surgery. Clin Perinatol 2017; 44: 72951.

2. Shetty P, Menezes LT, Tauro LF, Diddigi KA. Amniotic band syndrome. Indian J Surg 2012; 75: 401-2.

3. Pleș L, Sima R-M, Moisei C, Moga M, Dracea L, Moga MA. Pictorial essay Abnormal ultrasound appearance of the amniotic membranes-diagnostic and significance: a pictorial essay. Med Ultrason 2017; 19: 211-15.

4. Cortez-Ortega C, Garrocho-Rangel JA, FloresVelázquez J et al. Management of the Amniotic Band Syndrome with Cleft Palate: Literature Review and Report of a Case. Case Report Dent 2017; 2017: 7620416.

5. Guzmán-Huerta ME, Muro-Barragán SA, AcevedoGallegos S et al. Amniotic band sequence: prenatal diagnosis, phenotype descriptions, and a proposal of a new classification based on morphologic findings. Rev Invest Clin 2013; 65: 300-6.

6. Barros M, Gorgal G, Machado AP, Ramalho C, Matias A, Montenegro N. Revisiting amniotic band sequence: a wide spectrum of manifestations. Fetal Diagn Ther 2014; 35: 51-6.

7. Koskimies E, Syvänen J, Nietosvaara Y, Mäkitie O, Pakkasjärvi N. Congenital Constriction Band
Syndrome With Limb Defects. J Pediatr Orthop 2015; 35: 100-3.

8. Cignini P, Giorlandino C, Padula F, Dugo N, Cafà EV, Spata A. Epidemiology and risk factors of amniotic band syndrome, or ADAM sequence. J Prenatal Med 2012; 6: 59-63.

9. Barzilay E, Harel Y, Haas J et al. Prenatal diagnosis of amniotic band syndrome - risk factors and ultrasonic signs. J Matern Neonatal Med 2015; 28: 281-3.

10. Castilla EE, Lopez-Camelo JS, Campaña H. The altitude as a risk factor for congenital anomalies. Am J Med Genet 1999; 86: 9-14.

11. Daly CA, Freeman J, Weston $\mathrm{W}$ et al. Prenatal diagnosis of amniotic band syndrome in a methadone user: review of the literature and a case report. Ultrasound Obstet Gynecol 1996; 8: 123-5.

12. Rezai S, Faye J, Chadee A et al. Amniotic Band Syndrome, Perinatal Hospice, and Palliative Care versus Active Management. Case Report Obstet Gynecol 2016; 2016: 9756987.

13. Streeter GL. Focal deficiencies in fetal tissues and their relation to intrauterine amputations. Contrib Embryol Carnegie Inst 1930; 22: 1-44.

14. Torpin R. Amniochorionic mesoblastic fibrous strings and amniotic bands: Associated constricting 
fetal malformations or fetal death. Am J Obstet Gynaecol 1965; 91: 65-75.

15. Werler MM, Bosco JL, Shapira SK, National Birth Defects Prevention Study. Maternal vasoactive exposures, amniotic bands, and terminal transverse limb defects. Birth Defects Res A Clin Mol Teratol 2009; 85: 52-7.

16. Kennedy LA, Persaud TV. Pathogenesis of developmental defects induced in the rat by amniotic sac puncture. Acta Anat (Basel) 1977; 97: 23-35.

17. Halder A. Amniotic band syndrome and/or limb body wall complex: split or lump. Appl Clin Genet 2010; 3: 7-15.

18. Hvelplund C, Pihl K, Trautner S, Pedersen P, Maroun LL. Spontaneous Septostomy in a Twin Pregnancy Causing Fatal Amniotic Band Syndrome. Case Rep Pediatr 2018; 2018: 4549060.

19. Routhu M, Thakkallapelli S, Mohan P, Ahmed N. Role of Ultrasound in Body Stalk Anomaly and Amniotic Band Syndrome. Int'l J Reprod Med 2016; 2016: 3974139.

20. R D, Renukadevi TK. Amniotic Band Syndrome - A Dreaded Condition. J Clin Diagn Res 2016; 10: QD045.

21. Proffitt E, Phillips M, DeMauro C, Conde K, Powell J. Ultrasonographic Diagnosis of Intrauterine Fetal Decapitation Secondary to Amniotic Band Sequence: A Case Report. J Emerg Med 2016; 50: e129-31.

22. Nardozza LM, Araujo EJ, Caetano AC, Moron AF. Prenatal Diagnosis of Amniotic Band Syndrome in the Third Trimester of Pregnancy using 3D Ultrasound. J Clin Imaging Sci 2012; 2: 22.

23. Turğal M, Ozyüncü O, Yazıcıoğlu A, Onderoğlu LS. Integration of three-dimensional ultrasonography in the prenatal diagnosis of amniotic band syndrome: A case report. J Turk Ger Gynecol Assoc 2014; 15: 56-9.

24. Paladini D, Foglia S, Sglavo G, Martinelli P. Congenital constriction band of the upper arm: the role of three-dimensional ultrasound in diagnosis, counseling and multidisciplinary consultation. Ultrasound Obstet Gynecol 2004; 23: 520-2.

25. Inubashiri E, Hanaoka U, Kanenishi $\mathrm{K}$ et al. 3D and 4D sonographic imaging of amniotic band syndrome in early pregnancy. J Clin Ultrasound 2008; 36: 573-5.

26. Hata T, Tanaka H, Noguchi J. 3D/4D sonographic evaluation of amniotic band syndrome in early pregnancy: a supplement to 2D ultrasound. J Obstet Gynaecol Res 2011; 37: 656-60.

27. Krzyżanowski A, Kwiatek M, Gęca T, Barczyński B, Kwaśniewska A. Amniotic band syndrome in dichorionic diamniotic twin pregnancy. Hippokratia 2017; 21: 46-8.

28. Schlehe B, Elsässer M, Bosselmann S, Axt-Fliedner R, Sohn C, Kohl T. Complete chorioamniotic membrane separation with constrictive amniotic band sequence and partial extra-amniotic pregnancy: serial ultrasound documentation and successful fetoscopic intervention. J Perinatol 2014; 34: 941-4.

29. Derderian SC, Iqbal CW, Goldstein R, Lee H, Hirose S. Fetoscopic approach to amniotic band syndrome. J Pediatr Surg 2014; 49: 359-62.

30. Ananthan A, Athalye Jape G, Du Plessis J, Annear $\mathrm{P}$, Page R, Rao S. Amniotic band syndrome with pseudoarthrosis of tibia and fibula: A case report. Ir Med J 2017; 110: 570.

31. Belfort MA, Whitehead WE, Ball R et al. Fetoscopic Amniotic Band Release in a Case of Chorioamniotic Separation: An Innovative New Technique. Amer J Perinatol Reports 2016; 6: e222-5.

32. Iqbal CW, Derderian SC, Cheng Y, Lee H, Hirose S. Amniotic band syndrome: a single-institutional experience. Fetal Diagn Ther 2015; 37: 1-5.

33. Mathis J, Raio L, Baud D. Fetal laser therapy: applications in the management of fetal pathologies. Prenat Diagn 2015; 35: 623-36.

34. Javadian P, Shamshirsaz AA, Haeri S et al. Perinatal outcome after fetoscopic release of amniotic band - a single center experience and a review of the literature. Ultrasound Obstet Gynecol 2013; 42: 44955.

35. Chiu DTW, Patel A, Sakamoto S, Chu A. The Impact of Microsurgery on Congenital Hand Anomalies Associated with Amniotic Band Syndrome. Plast Reconstr Surg Glob Open 2018; 6: e1657.

36. Sentilhes L, Verspyck E, Patrier S et al. Maladie des brides amniotiques: étiopathogenie, diagnostic anténatal et prise en charge néonatale. J Gynecol Obstet Biol Reprod (Paris) 2003; 32: 693-704.

37. Zaré C, Traoré IA, Dakouré PW et al. Amniotic band syndrom at Bobo Dioulasso university teaching hospital (Burkina-Faso): about two cases. Pan Afr Med J 2015; 22: 187.

38. Hotwani K, Sharma K. Oral Rehabilitation for Amniotic Band Syndrome: An Unusual Presentation. Int'l J Clin Pediatr Dent 2015; 8: 55-7.

39. Vitale SG, Laganà AS, Rapisarda AMC, Padula F. Comment on Ultrasonographic Diagnosis of Intrauterine Fetal Decapitation Secondary to Amniotic Band Sequence: A Case Report. J Emerg Med 2016; 51: 191-2.

40. Ciloglu NS, Gumus N. A rare form of congenital amniotic band syndrome: total circular abdominal constriction band. Arch Plast Surg 2014; 41: 290-1.

41. Gargh K, Sullivan C, Laing H, Banerjee S. Congenital circumferential constriction band of the abdomen: a case report. Case Reports Med 2010; 2009: 825174.

42. Light TR, Ogden JA. Congenital constriction band syndrome. Pathophysiology and treatment. Yale J Biol Med 1993; 66: 143-55.

43. Pimenta J, Lapa P, Ramos L. Aplasia cutis congenita and amniotic band syndrome: an uncommon 
association. Brit Med J Case Reports 2017; 2017: bcr2016218950.

44. Shah KH, Shah H. A rare combination of amniotic constriction band with osteogenesis imperfecta. Brit Med J Case Reports 2015; 2015: bcr2015212400.

45. Das G, Gayen S, Bandyopadhyay S, Das D. Ethmocephaly with amniotic band syndrome. Middle East Afr J Ophthalmol 2012; 19: 429-31.

46. Chandran S, Lim MK, Yu VY. Fetal acalvaria with amniotic band syndrome. Arch Dis Child Fetal Neonatal Ed 2000; 82: F11-3.

47. Young ID, Lindenbaum RH, Thompson EM, Pembrey ME. Amniotic bands in connective tissue disorders. Arch Dis Child 1985; 60: 1061-3.
48. Murata $\mathrm{T}$, Hashimoto $\mathrm{S}$, Ishibashi $\mathrm{T}$, Inomata $\mathrm{H}$, Sueishi K. A case of amniotic band syndrome with bilateral epibulbar choristoma. Brit J Ophthalmol 1992; 76: 685-7.

49. Padmanabhan LD, Hamza Z V, Thampi MV, Nampoothiri S. Prenatal diagnosis of amniotic band syndrome. Indian J Radiol Imaging 2016; 26 : 63-6.

50. Gupta K, Venkatesan B, Chandra T, Rajeswari K, Devi TK. Amniotic band syndrome with sacral agenesis and umbilical cord entrapment: A case report emphasizing the value of evaluation of umbilical cord. J Radiol Case Reports 2015; 9: 12-9.

51. Uma R, Garg A, Patnaik SK. Amniotic band sequence--a debilitating syndrome. J Nepal Med Assoc 2012; 52: 178-80. 